\title{
BONE REPAIR FOLLOWING INJURY AND INFECTION *
}

\author{
FREDERIC W. BANCROFT, M.D. \\ Associate Attending Surgeon, New York Hospital \\ NEW YORK
}

Since McEwen's classical work on bone repair, there has been much uncertainty in the minds of clinicians regarding the process that occurs in bone repair following injury. Whether or not the periosteum is the all-important factor in osteogenesis has clouded our minds. The significance of the bone cell, of the periosteum, and the significance of intermembranous or of intercartilaginous bone development is not known. The terms after long usage are established as entities, thus tending to suggest biologic differences because of microscopic difference. Until the physical chemist gets at the root of things, confusion concerning bone in all parts of the body will exist in the minds of laboratory workers. I believe when the real secrets of bone formation are understood, we shall acknowledge that osteogenesis occurs in the same manner in all tissues. The tissues that are seemingly different under the microscope, I believe, are chemically similar whenever osteogenesis occurs, be it repair in a fracture or repair following infection, be it in periosteum, in muscle planes, in artery wall or in the ventricular septum of the heart. Stop and think of the confusion which necessarily follows, when at best only microscopic sections can be seen of the various complex tissues manifesting bone formation at single stages of each experiment. The physiologic chemist is handicapped in the same manner because his analysis by necessity is of a single stage, always involving many tissues. In the human being, and in the laboratory animal used for experiment, the tissues are far too complex in their functional activities and structural make-up to make it possible for the observer to deduce what happens in single cells such as may be present in osteogenesis; hence, the confusion among experimenters as expressed in the literature. The surgeon is too likely to feel that he does not know much about bone repair because he is so confused by the differences of opinion of the various experimenters. Those interested in osteogenesis are as often as not disputing over names and terms rather than discussing processes, and bone formation is truly a process and not a state.

* From the Laboratories of the Department of Surgery, Columbia University College of Physicians and Surgeons.

* Read before the Annual Meeting of the Colorado State Medical Society, Pueblo, Oct. 6, 1921. 


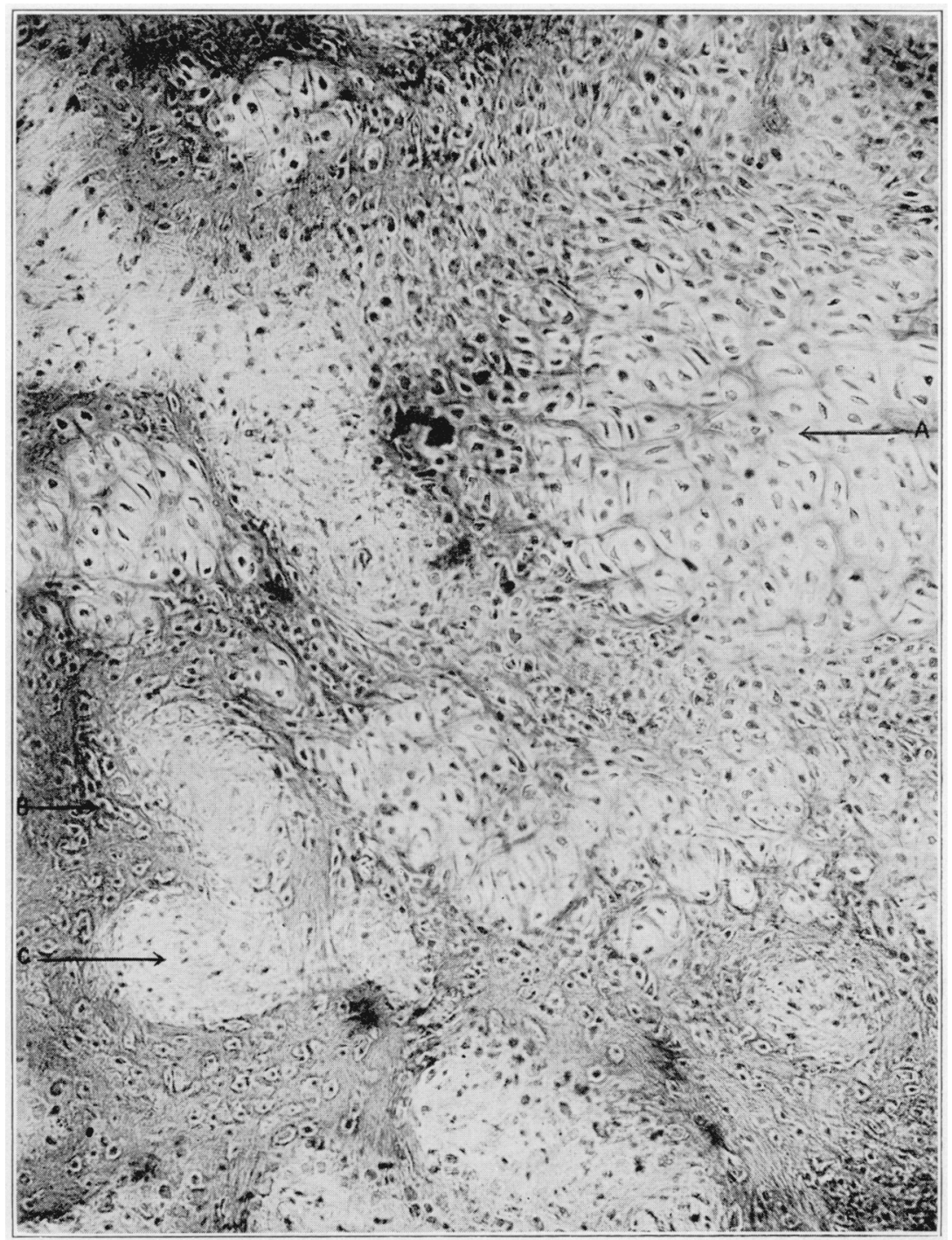

Fig. 1.-Farly bone formation following fracture: $A$, cartilage; $B$, new bone; $C$, connective tissue. Gradual transitions are observed from connective tissue to cartilage, from connective tissue to bone and from cartilage to bone. No distinctive cells are seen. 


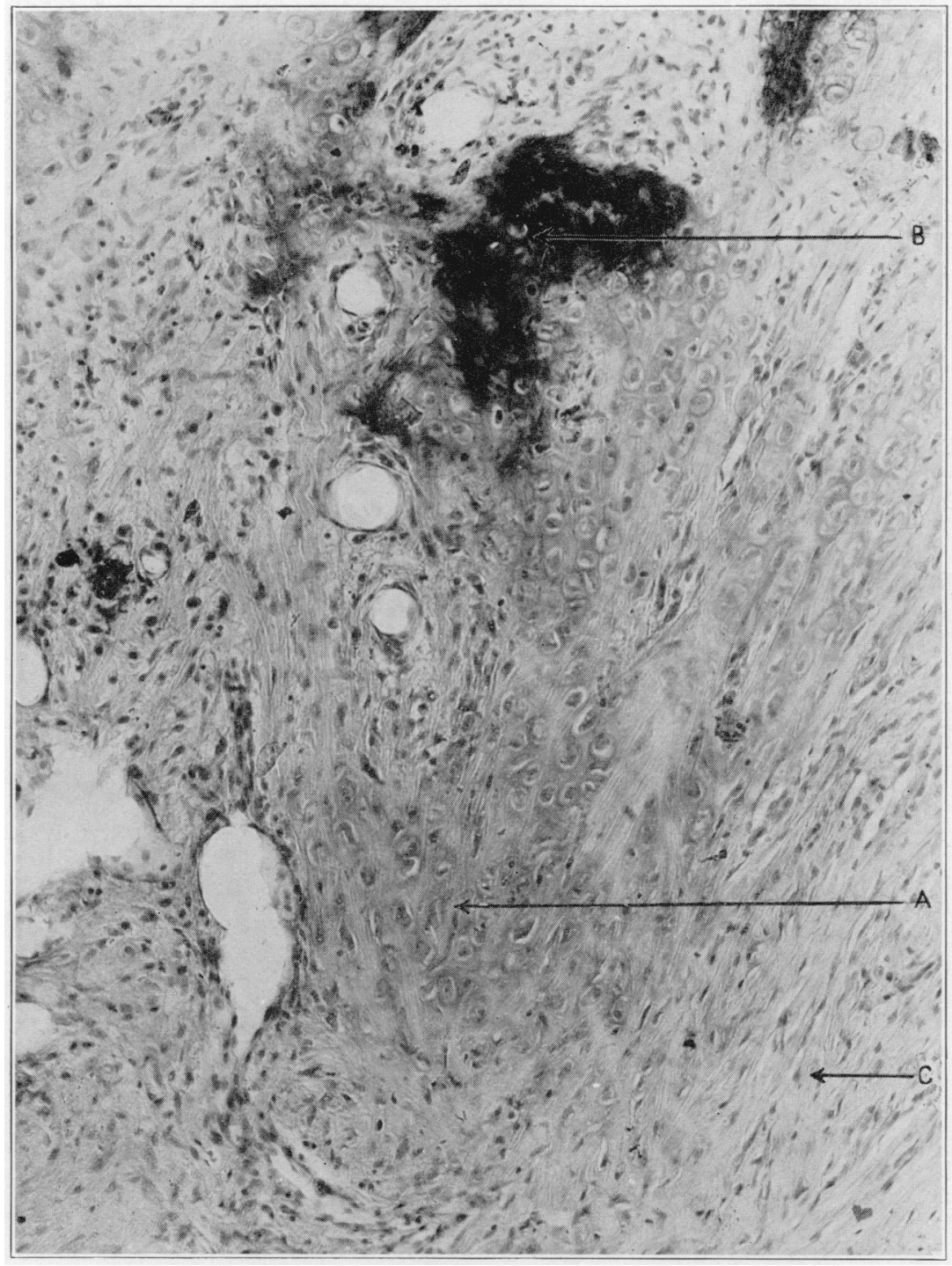

Fig. 2.-Scrapings removed from fractured humerus of a human being, twelve days after injury: $A$, fibrocartilage: $B$, carly bone: $C$, connective tissue 


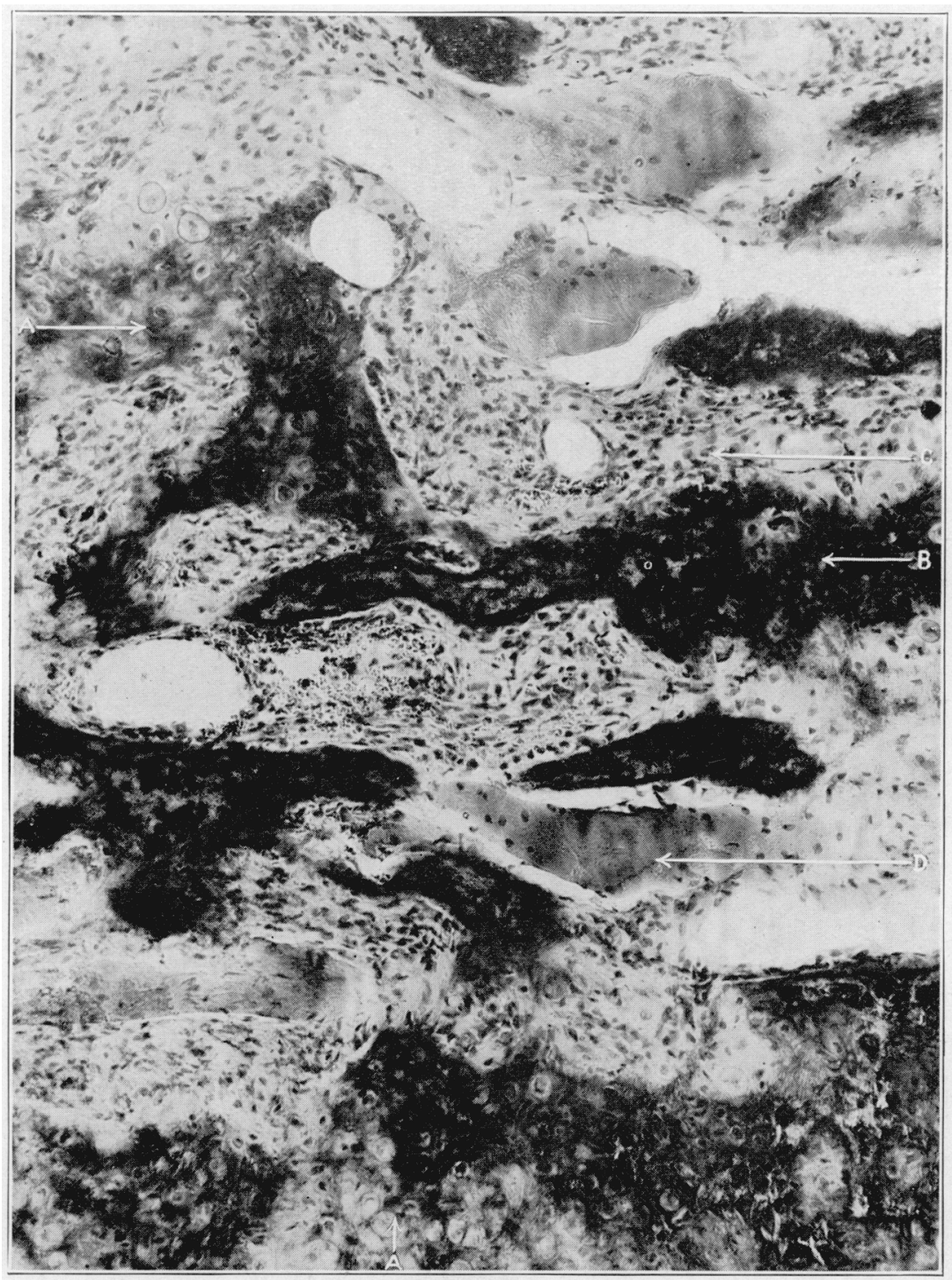

Fig. 3.-Ossification occurring in the midst of muscle fibers, twclve days following a fracture of the humerus in an adult: $A$, ossification occurring in cartilage: B, early bone: C, connective tissue; D. degenerating muscle fibers. 


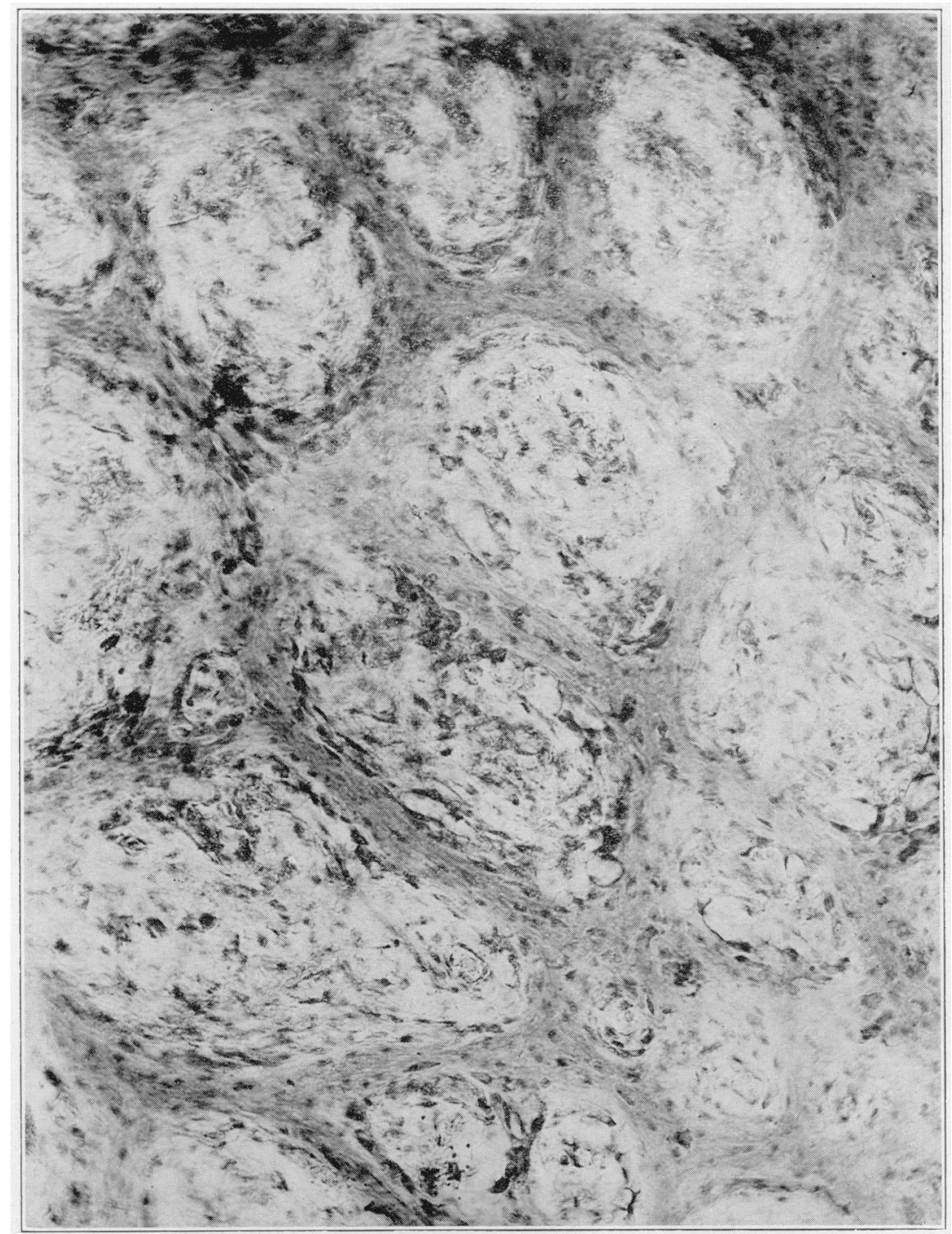

Fig. 4.-Callous formation seventeen days following fracture, showing deposition of calcium salts on the avascular zones in early connective tissue. 


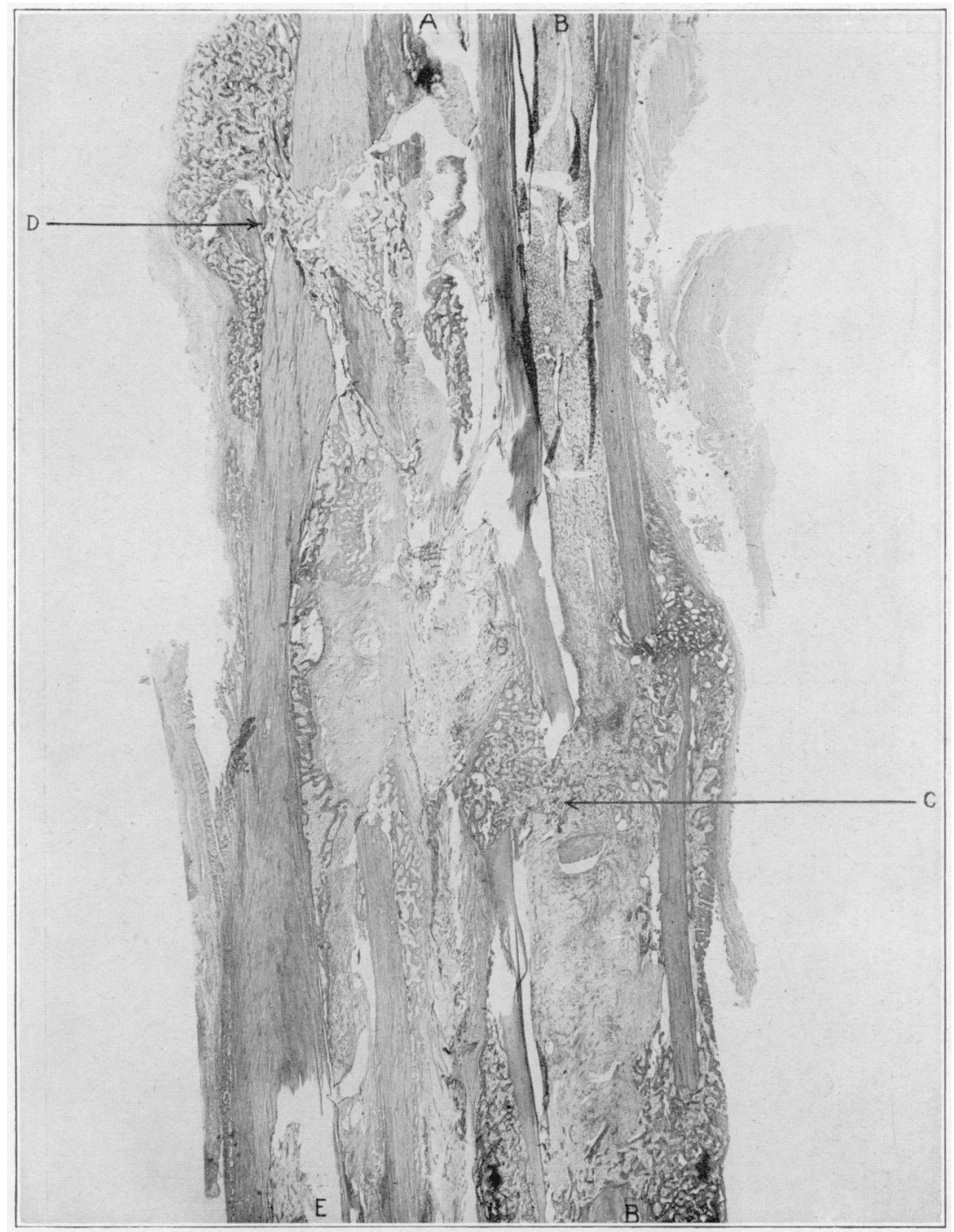

Fig. 5.-Comminuted fracture of radius and ulna in rabbit, fourteen days after injury: $A$, interosseous membrane; $B$, medullary canal of radius with cortex on either side; $C$, new bone forming in connective tissue following hemorrhage around the fractured ends and across the medullary canal; $D$, detached bone fragments surrounded by new bone formation; $E$, medullary canal of ulna. 


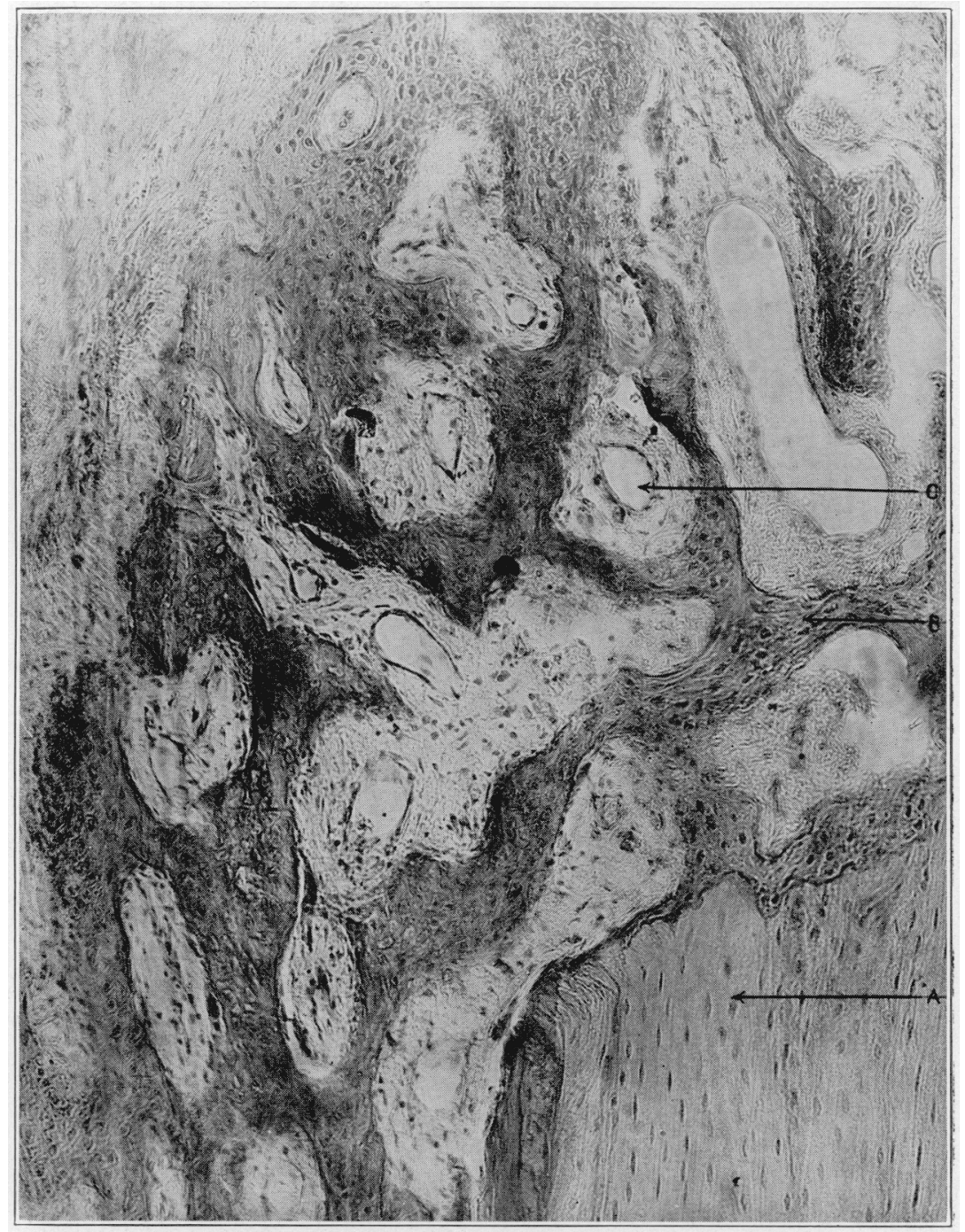

Fig. 6.-High power magnification of radius and ulna shown in Figure 5: $A$, end of fractured shaft showing atrophy at end with absence of bone nuclei; $B$, new bone formation in the connective tissue; $C$, arcolar connective tissue with newly formed lilood ressels. 


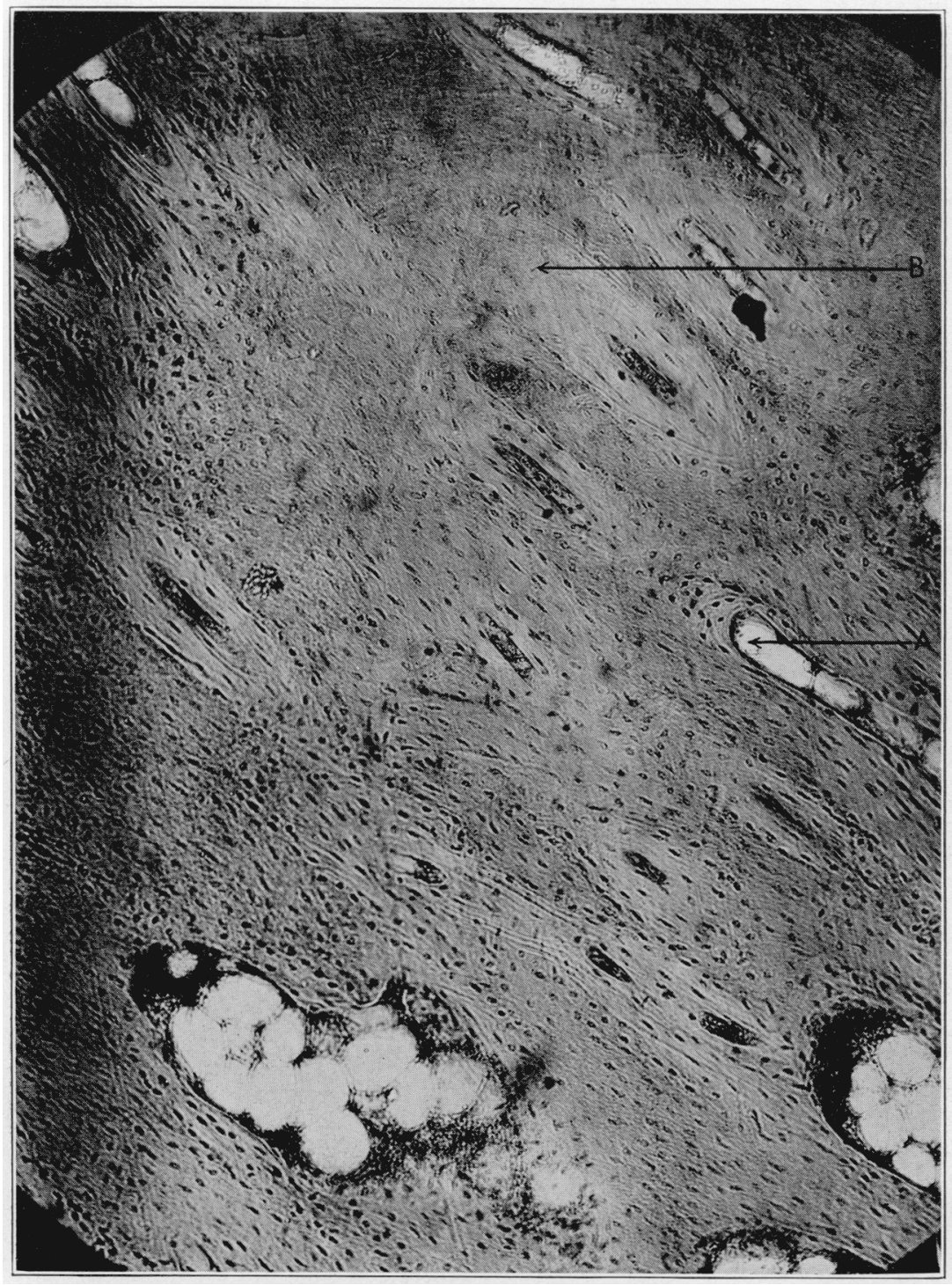

Fig, 7.-Bone transplants fonr wecks iollowing opretion: .1. haversian cand with restablishment of blood supply and surrounded by one or two lavers of active bone nuclei: $B$, ahsence of nuclei in bone distant irom haversian canal. 


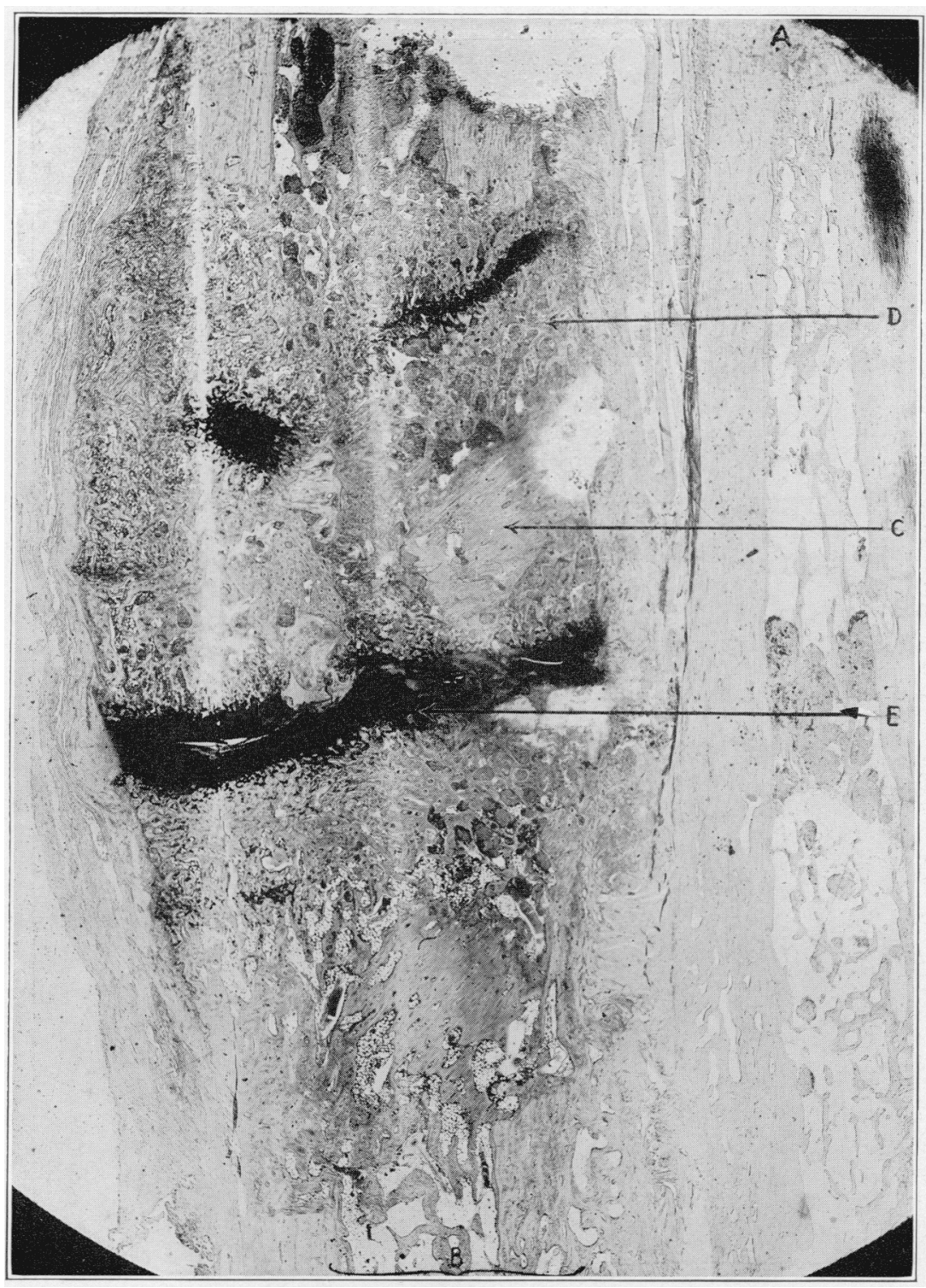

Fig. 8.-Transplantation of bone fragments to fill defect in radius, 141 days following operation: $A$, ulna; $B$, radius; $C$, bone fragment: nuclei do not stain; areas of rarefaction near periphery; $D$, new bone formation about periphery of fragments; li, cartilage forming false joint. 


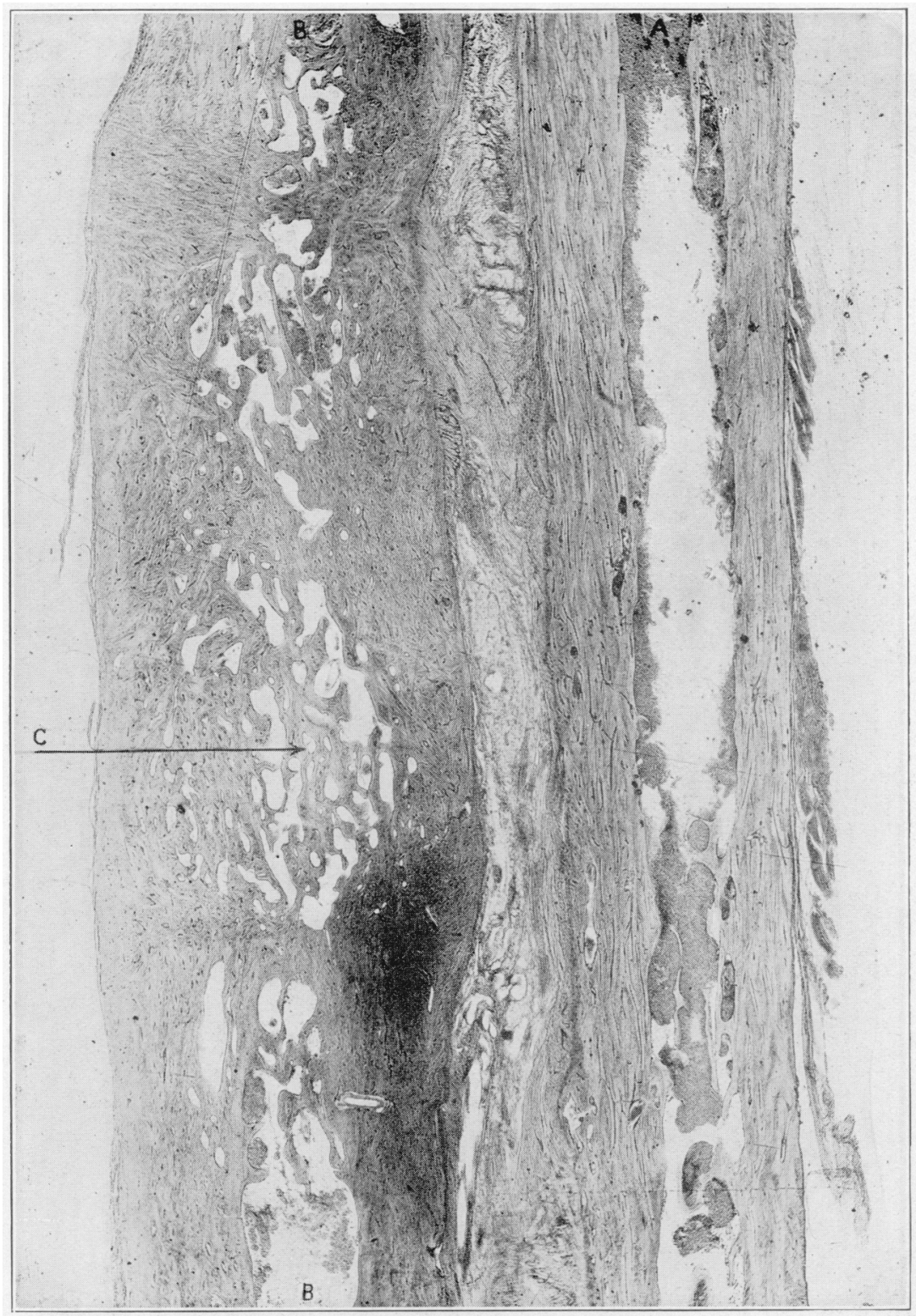

Fig. 9.-Transplantation of bone fragments to fill defect in radius, 347 days following operation: $A$, ulna; $B$, radius; $C$, beginning formation of medullary canal. The entire zone shown in the illustration is the area in which the transplants were placed. It is no longer possible to detect the fragments; but a new cortex and medullary canal are being established by the gradual absorption of the fragments and the formation of new bone. 
In order to have satisfactory therapeutic results, it is advisable to accept some practical working theory that will cover all types of bone formation. This theory should be broad enough not only to cover the skeletal bone formation but also the extraskeletal bone formation

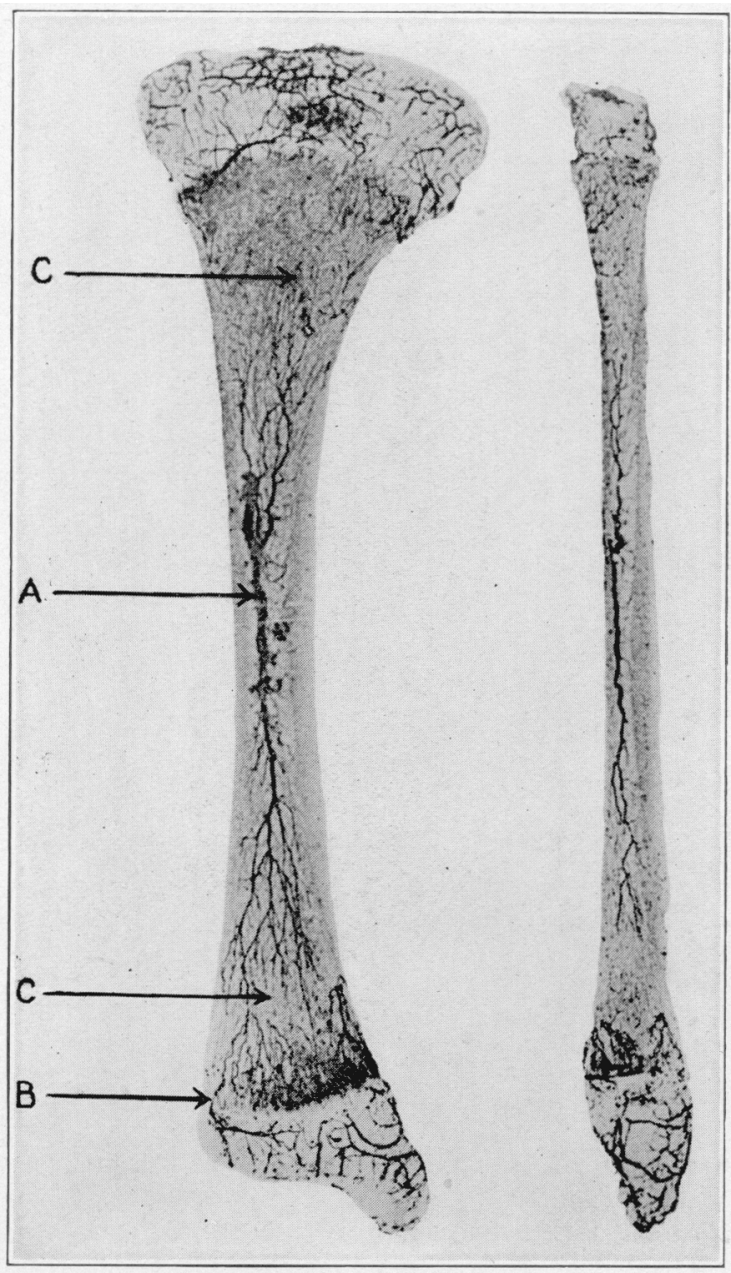

Fig. 10.-Circulation of infant's tibia and fibula (after Lexer): $A$, nutrient artery ; $B$, metaphyseal capsular artery ; $C$, relative avascular zone, where sequestrum separation usually occurs.

that occurs in so many places in the body. Extraskeletal bone formation occurs in one or more tissues in all of us if we live long enough. and it may be produced experimentally in animals without difficulty Extraskeletal bone occurs frequently in man in the arterial wall and 
in the muscles. It has been described as having been found in nearly all of the tissues of the body, such as the lymph nodes, ovaries, kidneys, fascial planes and wall of the orbit.

Experimentally, bone has been produced in animals by ligating the vessels of the kidney and wrapping the omentum about it. Microscopic sections of this kidney from one to two months later show areas of true bone and calcification occurring in the parenchyma. Neuhoff,

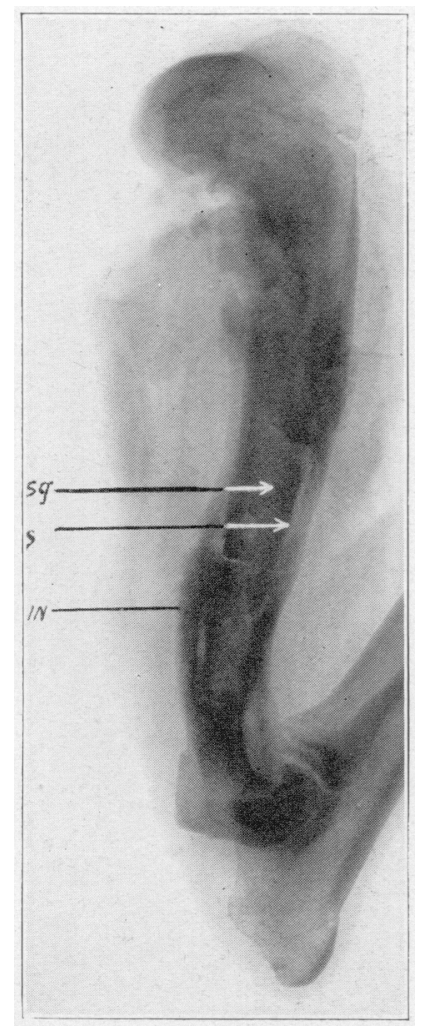

Fig. 11.-Roentgenogram of humerus, Nov. 3, 1919. Croton oil was inserted into the medullary canal in capillary tube containers, Oct. 10, 1919: $S Q$, sequestrum; In, involucrum; $S$, separation zone.

working in the laboratory of surgical research at Columbia University, found bone almost universally in fascia lata transplants that he had made to fill a defect in the bladder. Any theory, therefore, that we may accept should be broad enough to explain these irregular types of bone formation as well as the repair of bone following fractures and infection. We may, for the sake of discussion, classify the theories of bone repair roughly into three groups: (1) periosteal; (2) osteoblastic, and (3) extracellular deposition of calcium salts. 
1. The periosteal theory presupposes that the periosteum and endosteum are definite organs for bone formation and repair, and that the bone cells arise from them and from no other source.

2. The osteoblastic theory may be divided into two subtitles.

Type A. This assumes that in bone repair following injury bone cells are liberated from their lacunae and that they reproduce and form new bone.

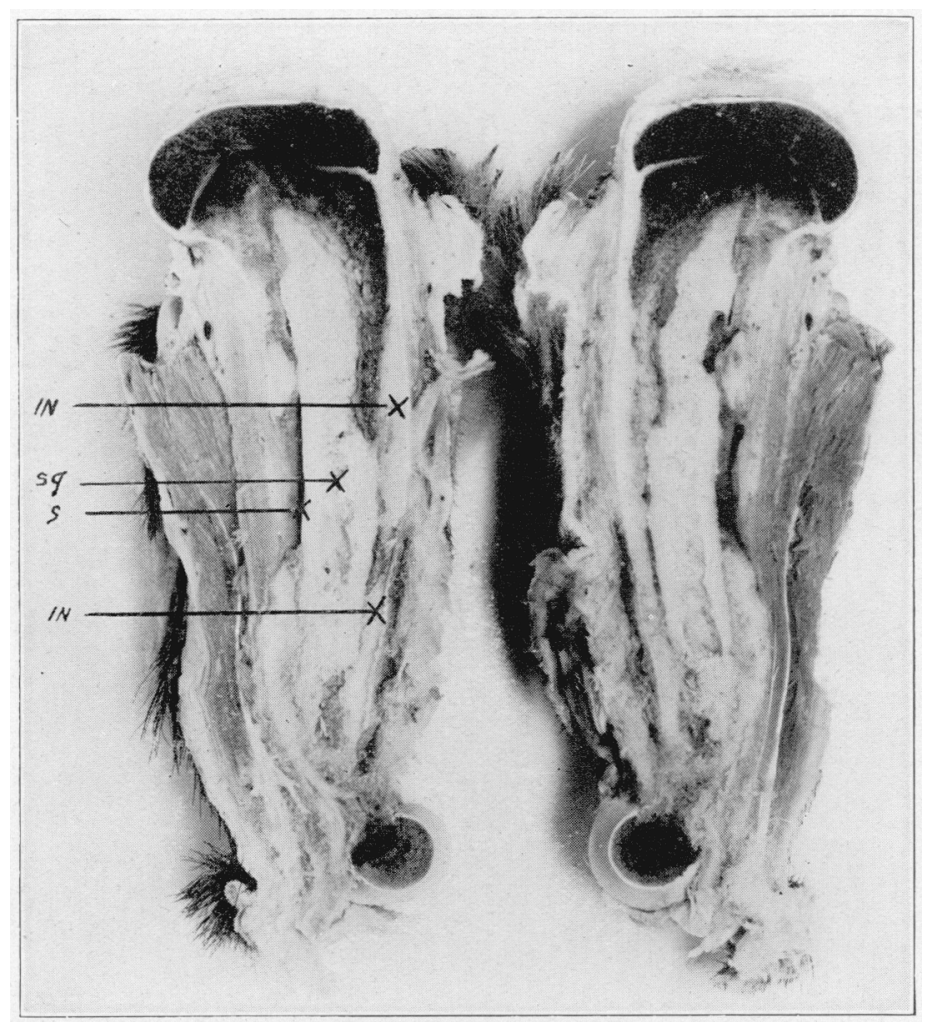

Fig. 12.-Cross-section showing massive sequestrum extending almost the entire length of the shaft; $S Q$, sequestrum; $I n$, involucrum; $S$, separation zone.

Type B. This assumes that following injury wandering connective tissue cells, fibroblasts, are drawn into the area of trauma. Owing to the stimulus of the repair, they are transformed into bone producing cells and then become specific cells.

3. The extracellular deposition of calcium salts theory assumes that there is no definite bone producing cell; that following injury, possibly by positive chemotaxis, calcium salts in the proportions usually found 


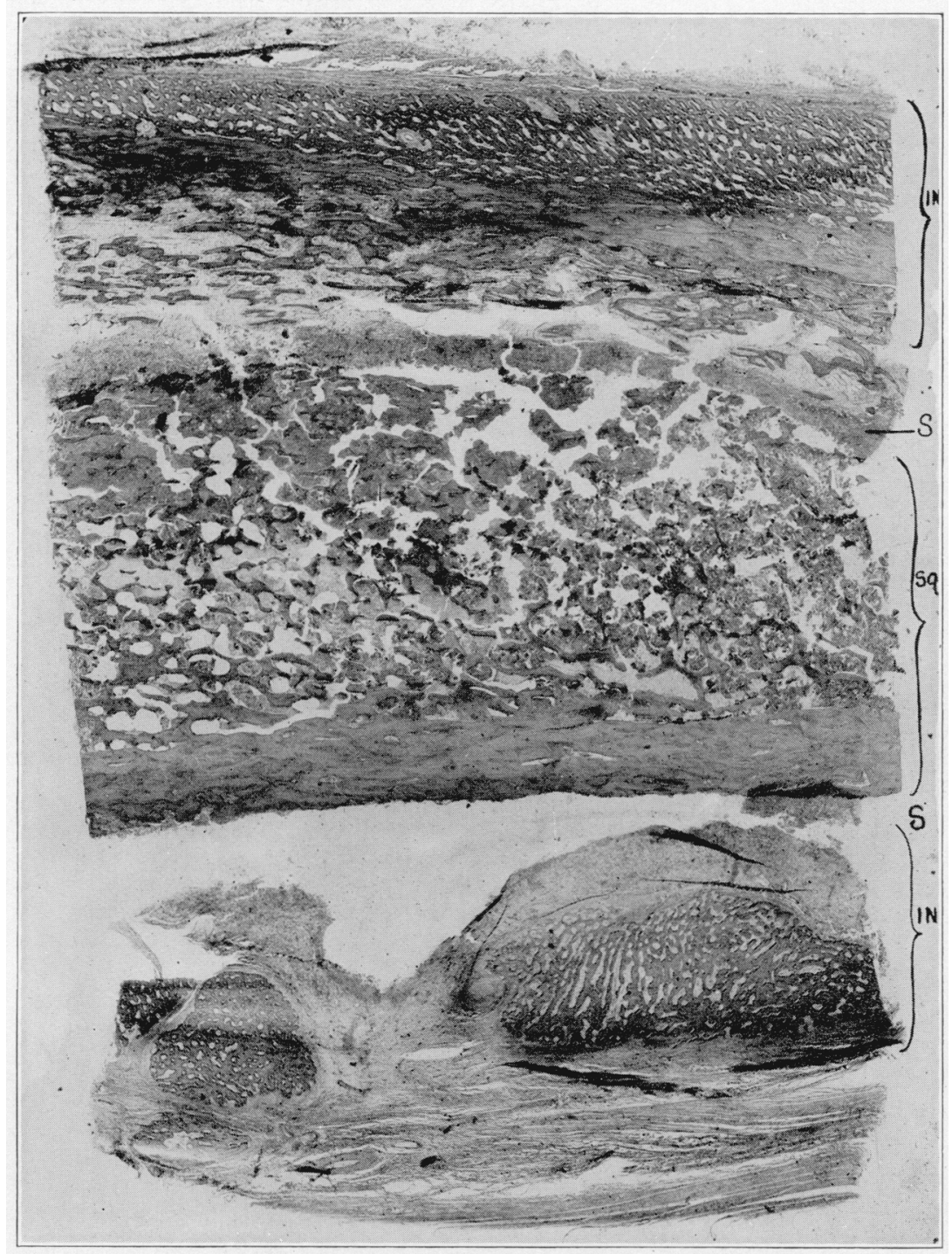

Fig. 13.- Microscopic section: Sq, secuestrum: In, involucrum; s, separation zone. lnder high power magnitication the hone nuclei in the secuestrum are absent and the mones in the medullary canal are filled with lenkocytes. The scparation zone \& contains débris and numerous polymorphonuclear leukocytes. In the lower separation zone $s$, clehris disappeared during the process of decalcitication. 
in bone are deposited in the extracellular frame-work of connective tissue and that the connective tissue cell then becomes a bone cell by functional adaptation.

Any one of these three theories may explain the ordinary repair of bone as seen in fractures; but it is difficult to explain under the periosteal theory the formation of extraskeletal bone.

The bone in fascia lata transplants in the bladder found by Neuhoff cannot be explained by the periosteal theory, and it is difficult to explain

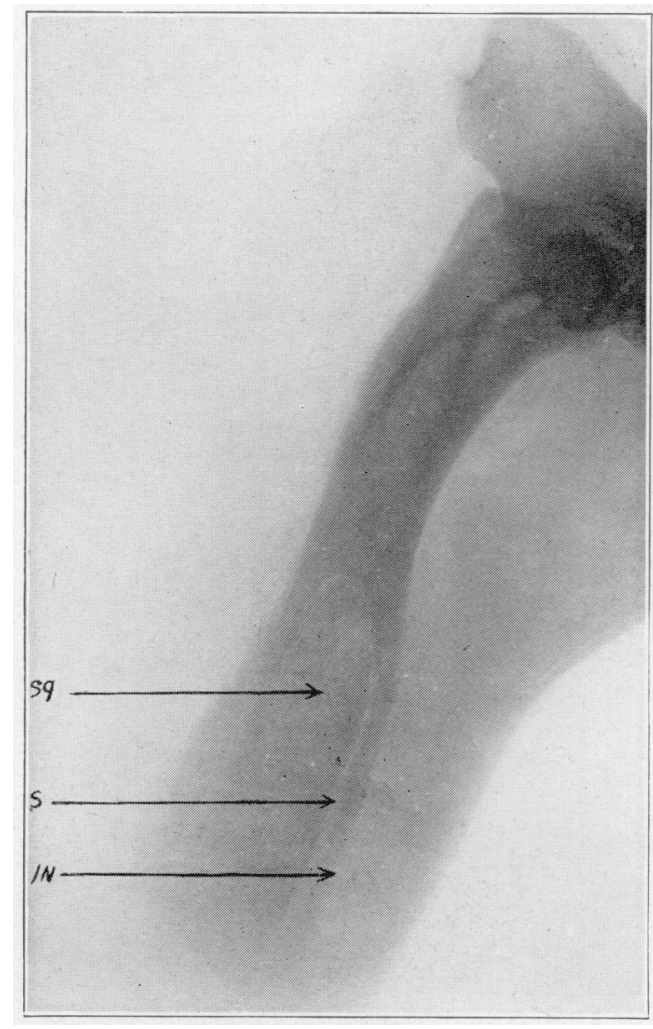

Fig. 14.-Following insertion of capillary tube containing croton oil, in medullary canal, Sept. 21, 1920. Roentgen ray. Large sequestrum in upper nalf of humerus, Oct. 15, 1920.

it if we assume that the osteoblast is a specific cell coming from other bone cells. Moreover, it is impossible to explain the formation of bone in the arteries of human beings, in the lymph nodes or in the kidney by either of these theories.

If we assume that bone is formed by metaplasia of connective tissue cells into osteogenetic cells or if we assume that it is purely a chemicai deposition in living connective tissue, we may explain the phenomenon very easily. 
The third theory has seemed more plausible to me. Gideon Wells has shown that if cartilage is transplanted into the omentum it has a greater power of absorbing calcium from the blood than has any other tissue similarly placed. He believes that the same proportions of calcium phosphate and calcium carbonate are present in the ash. of calcified material as bone, the main difference being that calcification occurs in dead tissue while ossification occurs in the presence of living tissue. In sections of kidneys in which the vessels have been ligaterl.

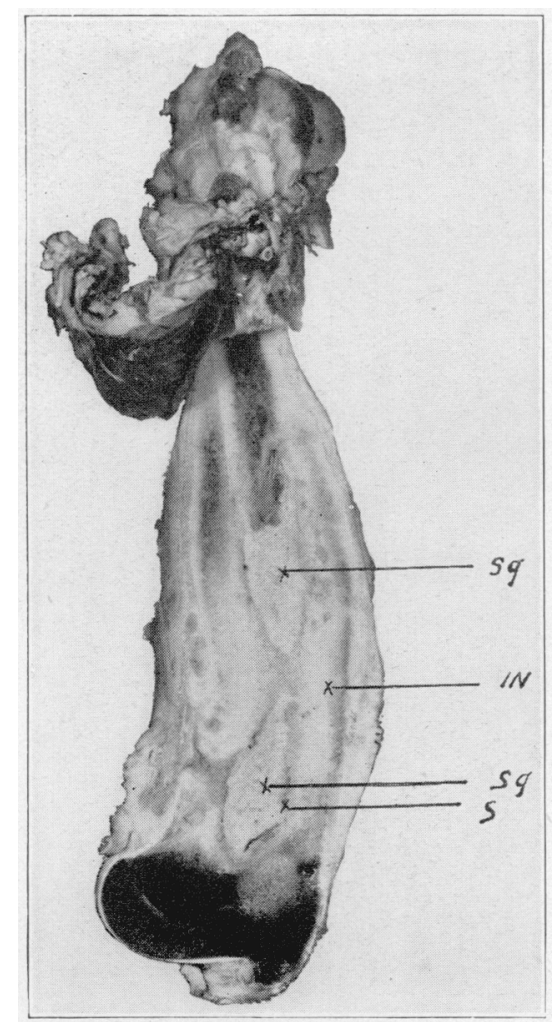

Fig. 15.-Cross-section showing massive sequestrum, with thick involucrum and zone of separation: $S Q$, sequestrum; $I n$, involucrum; $S$, zone of separation.

there are zones of calcification and ossification, the calcification occurring in dead tissue and ossification occurring where living bone cells are observed.

The simplest type of bone repair is seen following fractures. In a series of fractures on animals, I have been able to follow the repair at various stages. Immediately following the fractures, there is hemorrhage between the broken ends. Fibrin is then deposited and con- 
traction of the clot occurs. In from about five to ten days the organization of the clot by the ingrowth of connective tissue occurs. Connective tissue appears to take a definite lobulated arrangement, so that if we look at a cut section, we find blood ressels and then areas of thin areolar connective tissue (Figs. 1 to 4 ).

Calcium salts are then deposited in the avascular zones between the blood vessels. Farly callus looks very much like the lobules of the

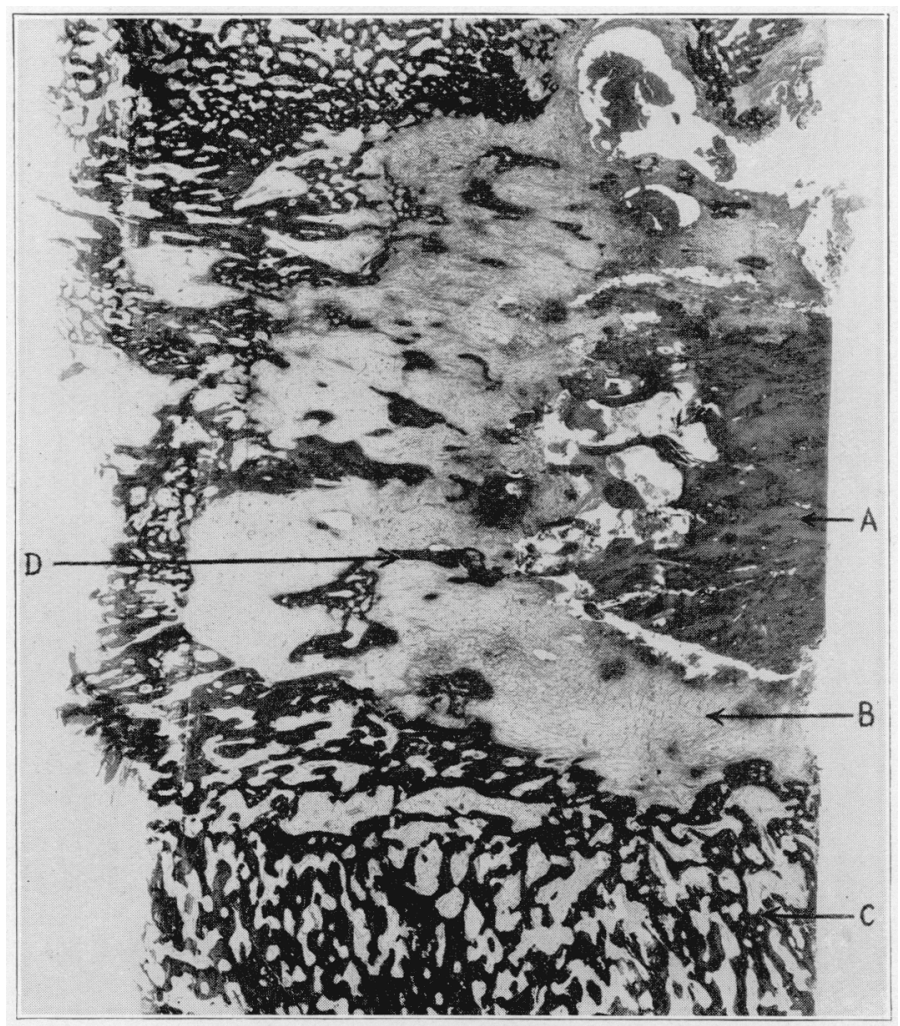

Fig. 16.--Lower power magnilication of terminal portion of secuestrum with surrounding involucrum: $A$, sequestrum: $B$, granulation tissue: $C$, involucrum: $D$, terminal spicule of sequestrum shown under high power in Figure 17.

liver. At first the blood vessels appear about this area of areolar tissue and then an area of new bone appears. It a later period. the areolar zone is almost completely replaced by osteogenetic tissue. This process continues until there is a definite haversian canal system of adult bone. In the zones of exuberant callous formation, absorption of the calcium salts takes place and scar tissue results. Bone atrophy occurs almost universally near the fratured ends. A great number of nuclei of the bone cells in the lacunate disappear. 


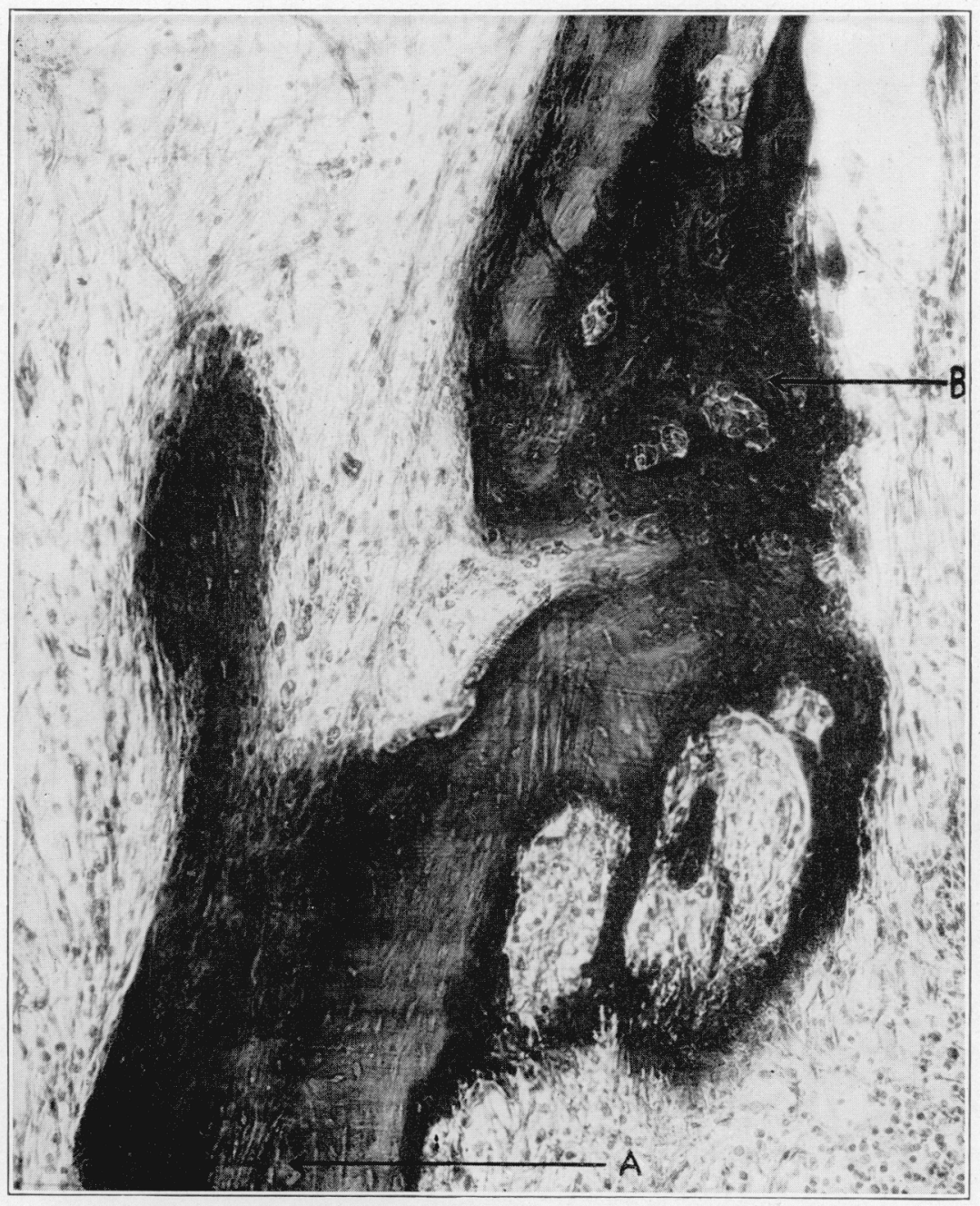

Fig. 17. - Terminal portion of secuestrum showing new lune formation alout it, and gradual reorganiation: . 1. cleal hone. cell spaces are empty showing no nuclear stain: $B$, newly formed bone surrounding and incorporating dead bone. 
As the granulation tissue springs from the periphery and the new blood vessels run at right angles to the shaft, the haversian canals as seen by microscopic examination from three to five months following fracture, are perpendicular to the normal haversian canals of the shaft. At the end of a year, however, by a gradual process of absorption and new formation, canals are reestablished in a normal direction. Periosteum, as it is a connective tissue and as it has an areolar layer

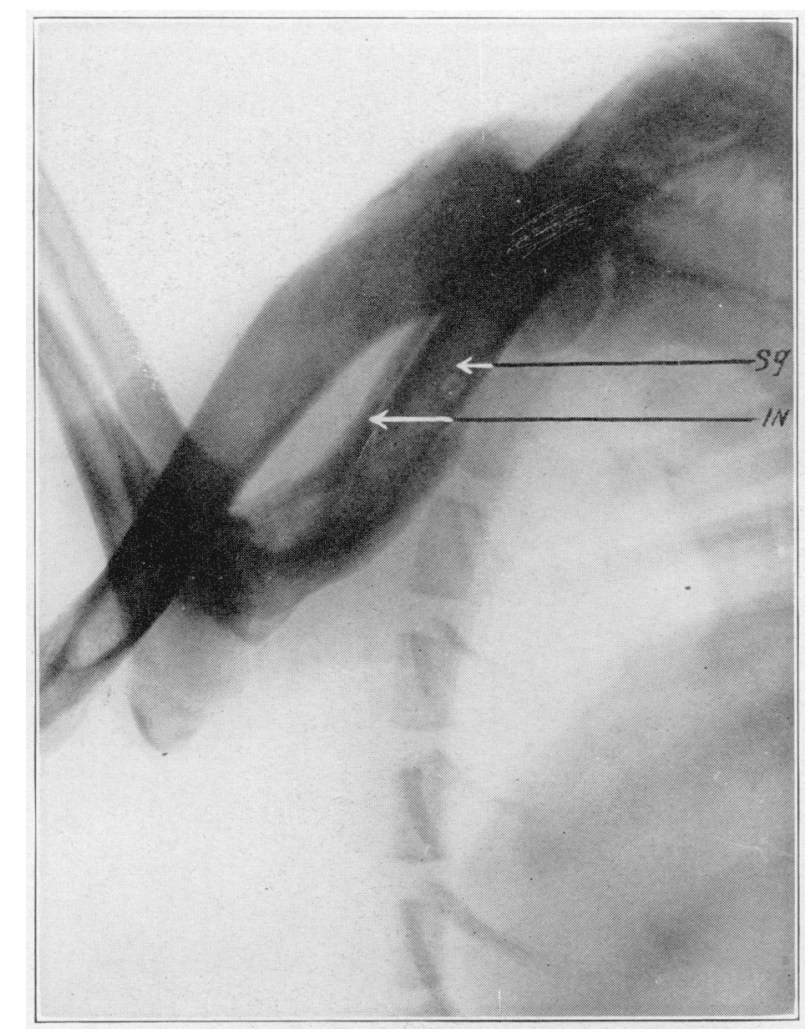

Fig. 18.-Large sequestrum, Nov. 10, 1919, with well marked involucrum and separation zone: $I n$, involucrum; $S q$, sequestrum; operation performed, Oct. $10,1919$.

immediately adjacent to the shaft, undoubtedly serves as a bone forming membrane; but it is not the only connective tissue which may form bone (Figs. 5 and 6 ).

The study of bone grafts shows strikingly why the clinician and the laboratory worker have differed in their accounts of the after-history of the graft.

The clinician has usually stated that grafts "live," because if occasion should arise clemanding the performance of a secondary operation, 
he finds that the cut section of the graft bleeds and that it has the general appearance of living bone. Roentgenograms also show the graft appearing as normal bone.

The laboratory worker on microscopic examination finds that in grafts of one to two weeks' duration the nuclei do not stain and the bone appears dead. Microscopic examination at a later period reveals the blood vessels reestablished in the haversian canals, and about them one or two layers of living bone cells, while portions of the graft

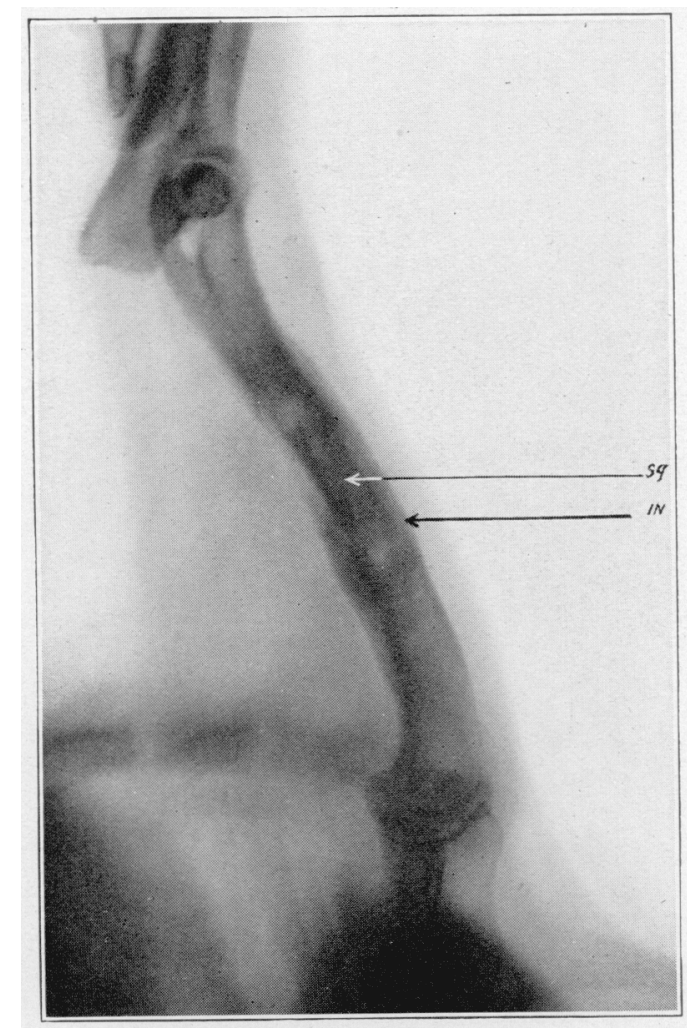

Fig. 19.-Sequestrum and involucrum, Dec. 1, 1919, less marked than previously: $I n$, involucrum; $S q$, sequestrum.

further from the canais show the absence of nuclei (Fig. 7). The process then continues as a gradual absorption of the dead bone and the formation of new bone in its place. It is easy to see that the bone at this period would bleed on section and would appear alive clinically.

In order to have a successful graft, three conditions must be established: First, the graft must maintain the shape of the limb; second, it must have its blood supply quickly reestablished and, third, it must stimulate osteogenesis in the neighboring tissues. 
McWilliams, in a thorough analysis of the various methods of bone grafting, read before the American Surgical Association at Toronto in June, 1921, came to the conclusion that the presence of periosteum upon the graft had very little influence upon its ultimate success. He analyzed about 1,390 cases in which grafts had been used. Of these, 1,170, with 82.9 per cent. of successes, had periosteum, while 196, with 82.6 per cent. of successes, were without periosteum. In

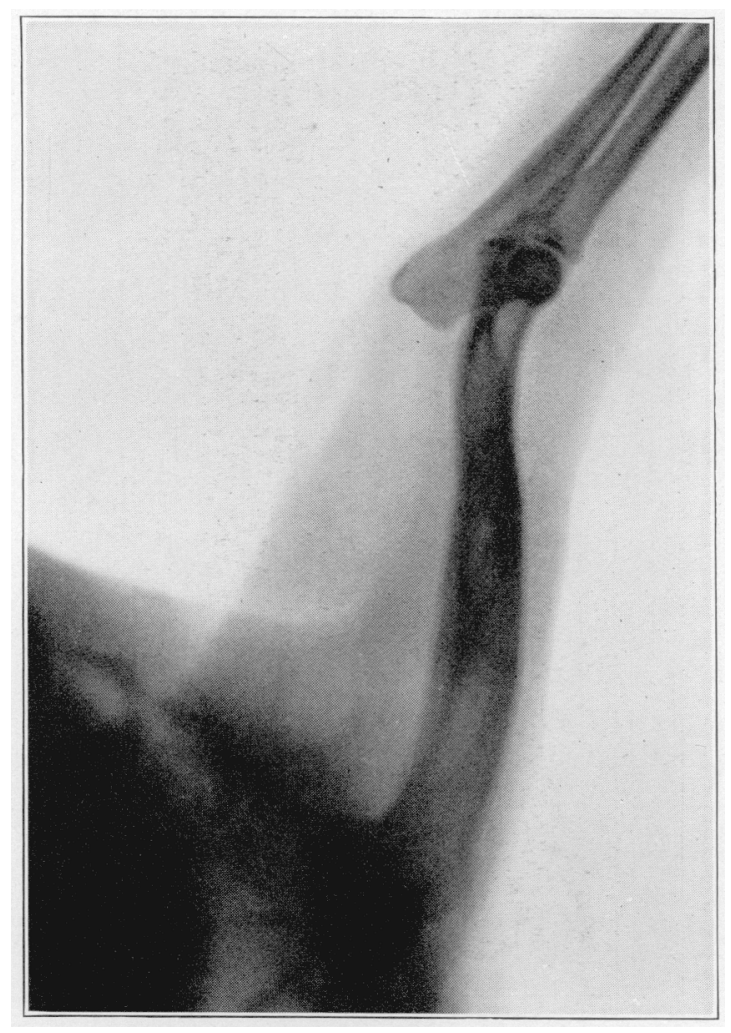

Fig. 20.-Roentgenogram, Jan. 15, 1920; no involucrum or sequestrum seen.

analyzing the types of transplants, he found that the successes were relatively as follows: bone pegs, 95.8 per cent.; osteoperiosteal (Ollier, DeLangeniere), 87.3 per cent.; end-to-end (without inlay), 82.5 per cent. ; inlay, 80.9 per cent., and intramedullary, 76.6 per cent.

If we study these, we find that probably the three points emphasized for the success of bone grafts explain the relative success of the foregoing methods. 
Bone pegs are surrounded completely by bone and very quickly have their blood supply reestablished.

The osteoperiosteal grafts of DeLangeniere are thin strips of bone and periosteum which are laid down between the ends of the bone. If they are sufficient to maintain the shape of the limb, theoretically they are the most practical, for the blood supply is very quickly established. They offer a large surface of raw bone to stimulate osteogenesis.

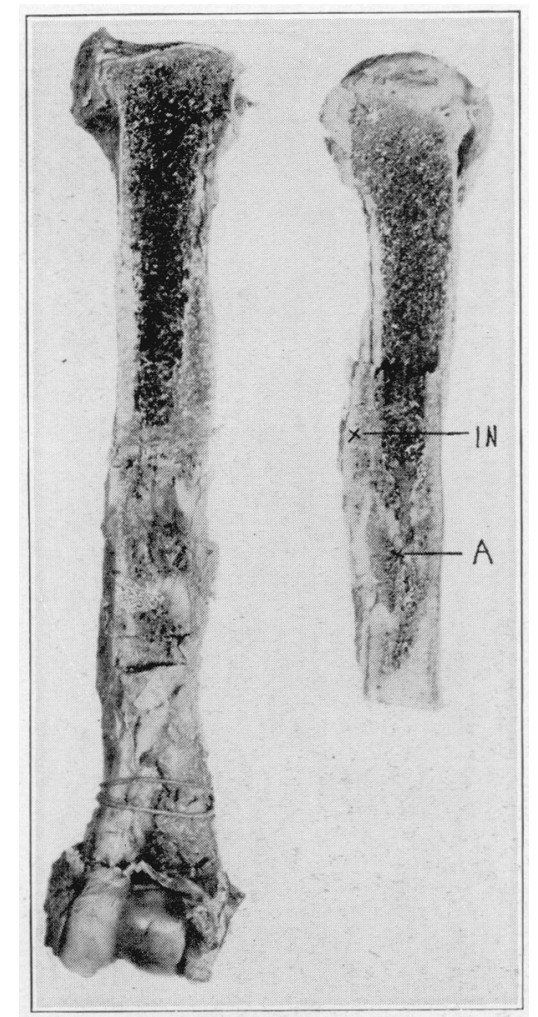

Fig. 21.-Cut-section, Jan. 24, 1920: In, subperiosteal bone proliferation; $A$, probable remnants of old sequestrum but no separation zone.

The inlay graft is, as a rule, rather thick and does not offer so much surface of raw bone for stimulation of osteogenesis. The late fractures that occur in these cases are probably due to the slow reestablishment of the blood supply and the resulting atrophy of the transplant.

I am inclined to believe that the intramedullary graft should be condemned. We know that the main blood supply of the shaft of the long bone is from the nutrient artery. In applying an intramedullary 
graft, we destroy the blood supply of both fractured ends of the shaft and undoubtedly a longer time is required for repair on account of this to reestablish the blood supply of the graft.

In a series of experiments lasting over two or three years, I transplanted small bone fragments into a defect of from 1 to 2 inches $(2.5$ to $5 \mathrm{~cm}$.) in the radii of dogs. Microscopic studies made at various intervals after operation showed, in the early stages, absence of the nuclei in all these grafts. There was, however, marked production

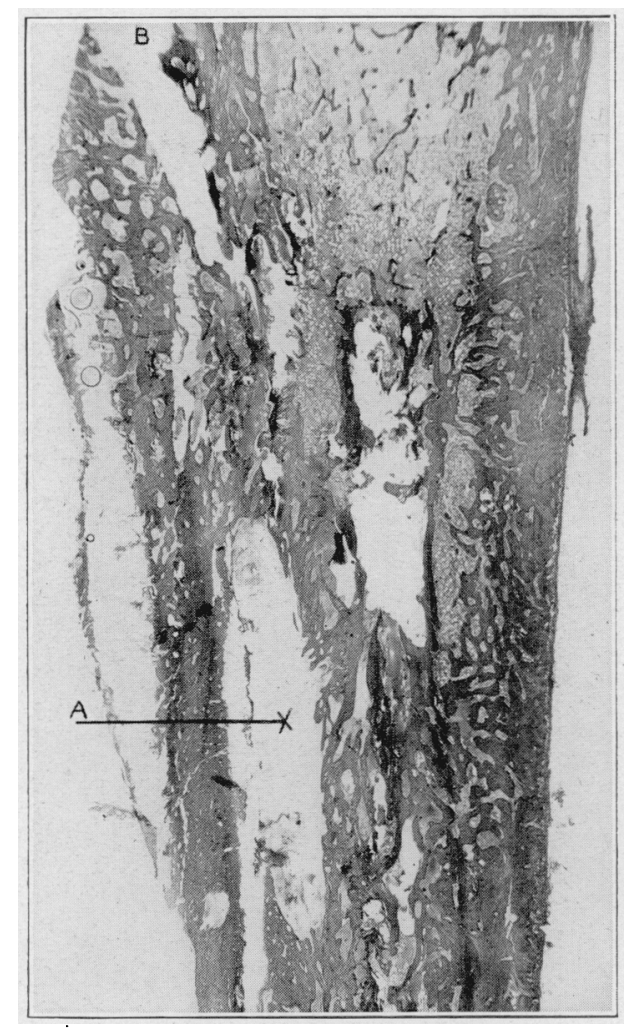

Fig. 22.-Microscopic section showing sulbperiosteal bone proliferation, no zone of separation: $A$, spaces in which capillary tubes lay; $B$, artefact occurring during decalcification.

of new bone about them in the granulation tissue produced immediately after operation. Firm union was the ultimate result in nearly all of these cases.

At the end of about a month, blood vessels were seen in the haversian canals of the fragments, and about each of these canals were seen two of three layers of bone cells with active nuclei. I believe that these grafts act in a manner similar to the osteoperiosteal grafts of DeLangeniere (Figs. 8 and 9). 


\section{OSTEOMYELITIS}

At the present time, when radicalism is necessary in the treatment of chronic osteomyelitis in alults, I believe a word of caution should be spoken with regard to the treatment of hematogenous ostemyelitis in children.

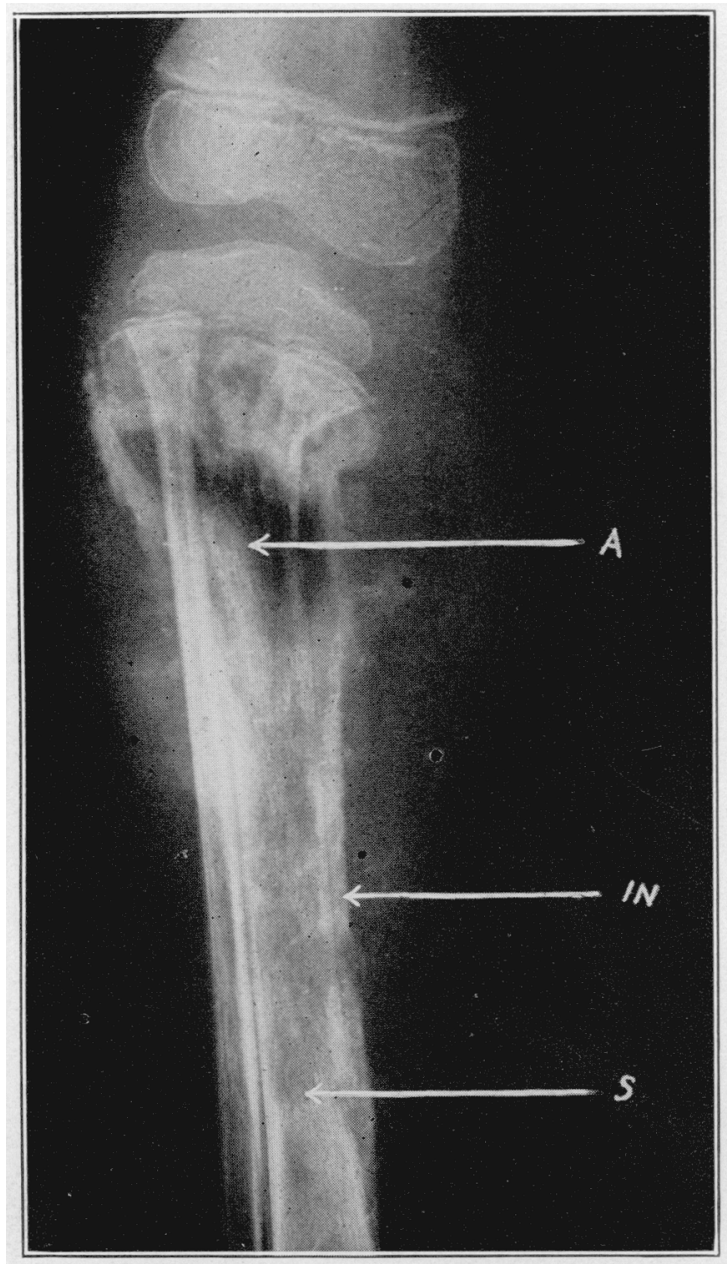

Fig. 23 (Case 1).-Roentgenogram, taken July 30. 1919; operation performed June 22, 1919, consisting of removal of 2 inches $(5 \mathrm{~cm}$.) of anterior surface of the uper third of the tibia: $A$, area of bone removed at primary operation; $I n$, involucrum; $\$$, separation zone.

The treatment of acute osteomyelitis in children may properly be divided into the treatment at the acute, and treatment at the subacute, stage. The primary indication for operation at the onset is the relief of pus under pressure, and as such, it requires the application of the 
same surgical principles ats pus collections elsewhere in the body, that is, adequate drainage, with the least possible trauma and with careful attention to the blood supply. If one considers that frequently periosteum with its blood supply has been stripped from the shaft by the exudation of pus and that the only remaining blood supply to the shaft is through the nutrient artery, one realizes the danger to the entire shaft of too active treatment by curettage or packing (Fig. 10).

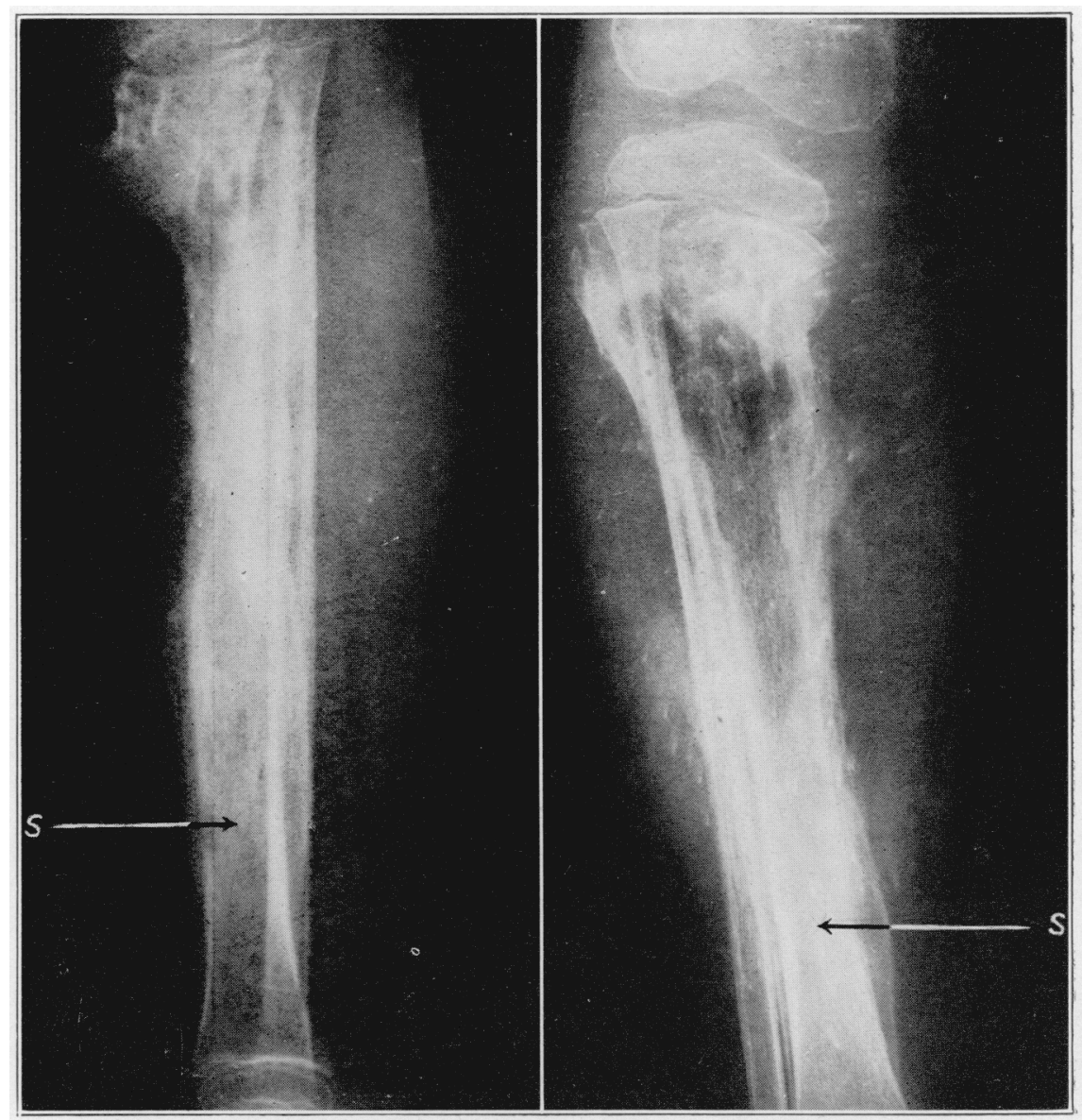

Fig. 24 (Case 1),--Operation, June 22. 1919: rocntgenogram taken Aug. 22, 1919: S, former separation zone: marked subperiosteal proliferation. No operative procedure has been performed on this area.

It is true that in the region of the metaphysis, the bony septums somewhat resemble the septums of the mastoid, and that, therefore, in this region it may be necessary to break up the compartments of the abscess. Care should be taken even here not to trammatize any more than possible. 
Constant, careful postoperative observation of these cases is necessary, as there are frequent secondary metastatic abscesses in the soft parts.

Subacute Stage.-Before the days of wound sterilization, the course of a case could be fairly definitely prophesied. At the primary operation, the shaft was opened wide, frequently curetted and packed. Following this, sequestration occurred, frequently involving almost the entire shaft. As advised by Nichols, of Boston, the sequestrum was usually removed at a time when the involucrum was strong enough to

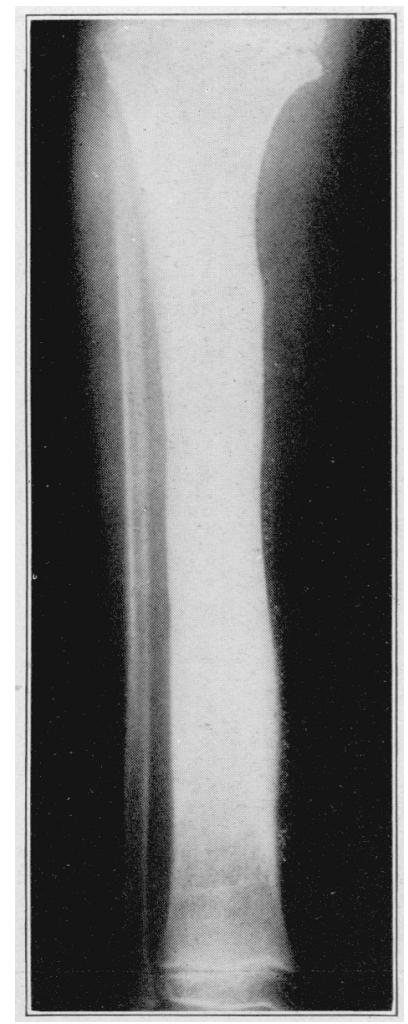

Fig. 25 (Case 1).-Operation, June 22, 1919; roentgenogram taken, Nov, 24, 1920; no sinus; patient apparently well.

maintain the shape of the limb, and yet, at such a stage when the involucrum could be inverted, obliterating, as far as possible, the "dead space."

In 1919, I attempted to reproduce osteomyelitis in dogs before the students of the third-year course in regional surgery at Columbia. At the suggestion of Dr. William C. Clarke of the department of surgery, through a drill hole in the cortex of the medullary canal of the humerus, 
croton oil was introduced in glass capillary tube containers having their ends sealed with agar-agar. The hole in the cortex was then plugged with bone wax, and the soft parts and the skin were sutured. By this procedure, repair following the operative trauma was allowed to progress before the croton oil was liberated from the capillary tube, probably by the solvent action of the cells and body fluids upon the agar-agar. As croton oil causes marked necrosis of the surrounding bone, we were able to produce a chemical osteomyelitis. A sequestrum,

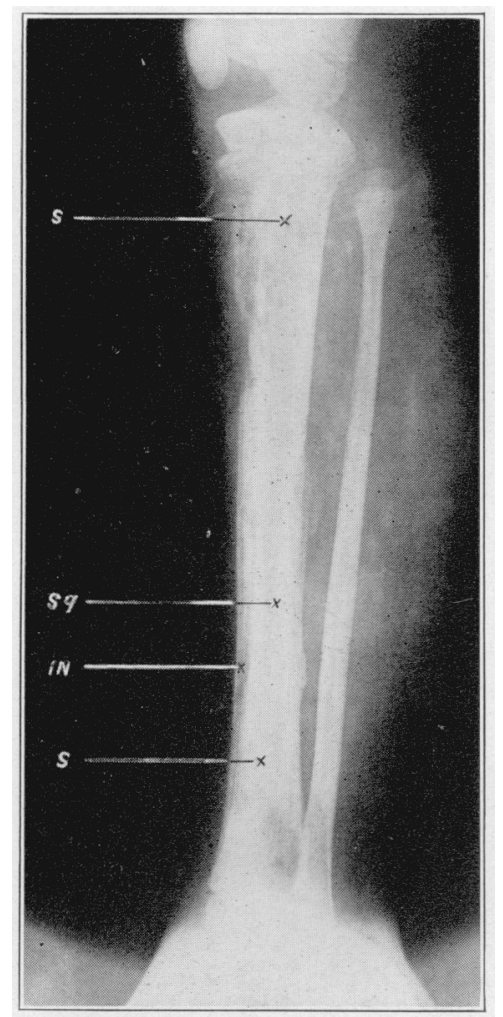

Fig. 26 (Case 2),- Roentgenogram taken, Dec. 8, 1919, previous to operation: $S q$, sequestrum; $I n$, involucrum; $S$, separation zone.

often from 5 to $10 \mathrm{~cm}$. in length, and including the entire circumference of the shaft, frequently occurred (Figs. 11 to 17). This sequestrum was separated from a newly formed involucrum by a zone of débris and leukocytes; therefore, all the factors of an acute osteomyelitis were present with the exception probably of bacteria and their by-products. Sections showed the sequestrum with an involucrum surrounding it but separated from it by a zone of pus. The cortical bone of sequestrum showed absence of nuclei, and throughout its cancellous portion there 
was a marked infiltration of leukocytes. The involucrum consisted of newly formed subperiosteal bone.

In the prolonged animal experiments roentgenologic studies showed the gradual disappearance of the sequestrum so that at the end of two months it was impossible to detect its former outlines by the roentgen ray (Figs. 18 to 22 ). Microscopic sections taken at this time showed the disappearance of the zone of separation; and the former sequestrum was then united to the living bone by blood vessels entering the

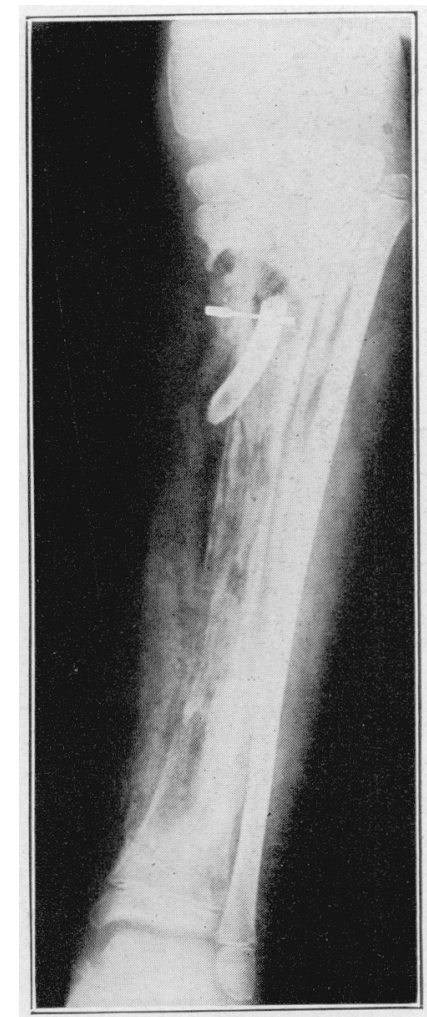

Fig. 27 (Case 2).-Roentgenogram taken, Feb. 7, 1920; operation, Dec. 9, 1919; anterior surface of the cortex of the tibia removed; drainage tube in popliteal space shown.

haversian canals. The process was similar to that found in any bone transplant, gradual absorption and deposition of new bone occurring throughout the haversian canals until all the dead bone had been replaced.

I have emphasized these facts because I believe they have a definite influence on human surgery. I shall show in the study of clinical cases that in children bone tissues that are apparently dead can be saved to advantage. 
Since the introduction of the (arrel-Dakin technic, we have had restalts on Dr. Pool's service at the New York Hospital which correspond to a certain degree with results found in our experimental work. The following two cases show marked regeneration of bone which on either roentgen-ray or gross examination appeared necrotic.

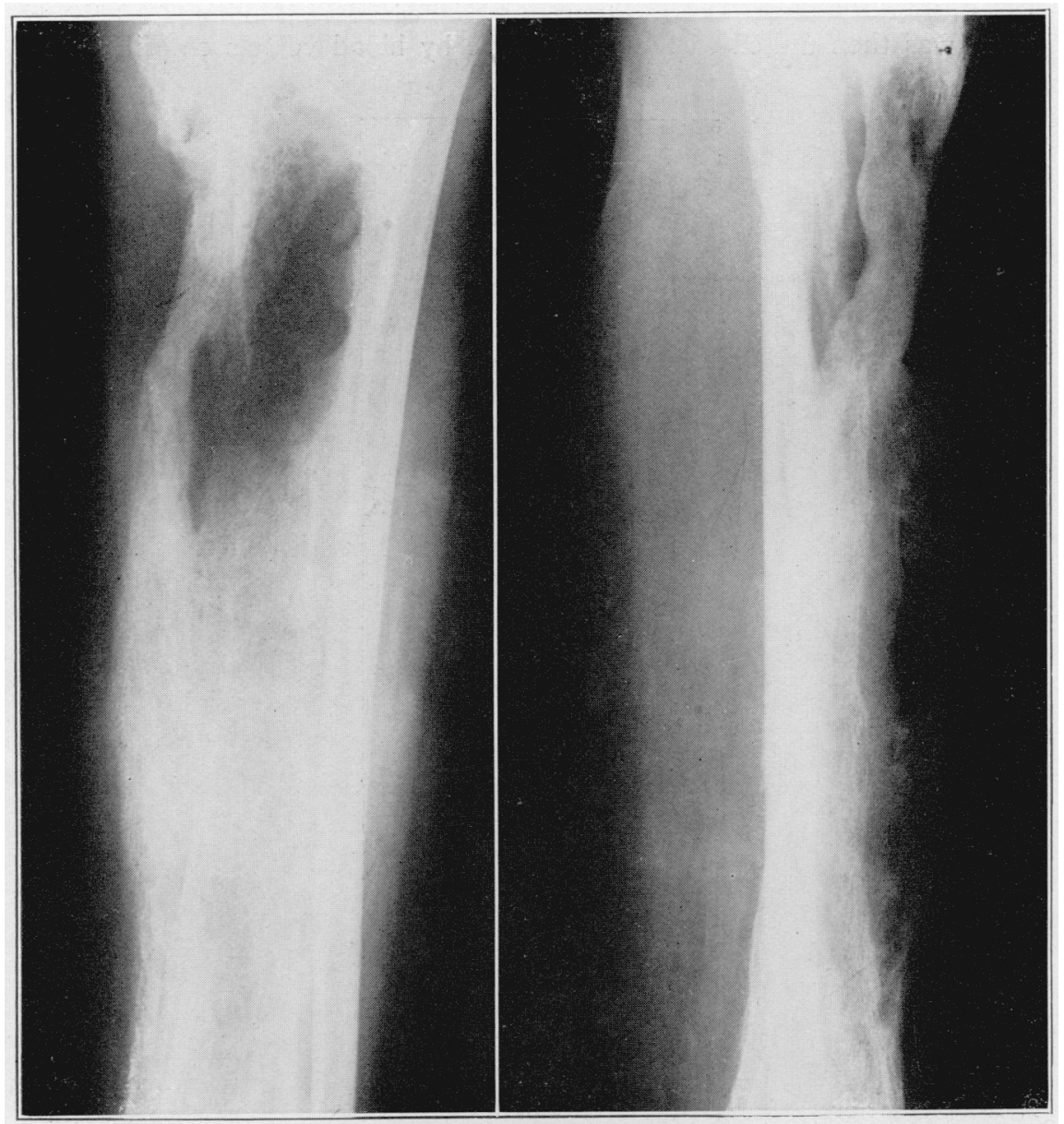

Fig. 28 (Case 2). -Roentgenogram taken, April 10, 1920; new bone proliferation about and incorporating former dead shaft.

On account of limited time, brief summaries of only two illustrative cases will be given.

$$
\text { RENORT OF C.ISES }
$$

Case 1 (Figs. 23, 24 and 25).-A girl, aged 5 years, came into the hespital with an acute osteonyelitis involving the upper third of the tilia. Drainage was estallished by removing the anterior part of the cortex in the upper 
third. Later, the roentgen ray revealed a marked rarefaction and apparent sequestrum formation in the lower third. As the temperature was approaching normal, and her condition was quite satisfactory, it was considered advisable to clelay operation on the lower third. Later the roentgen ray revealed subperiostcal bone proliferation around this zone of separation, and a roentgenogram one year later revealed a relatively normal appearing shaft. At the present time, she is well, without any sinus, and apparently the process is cured.

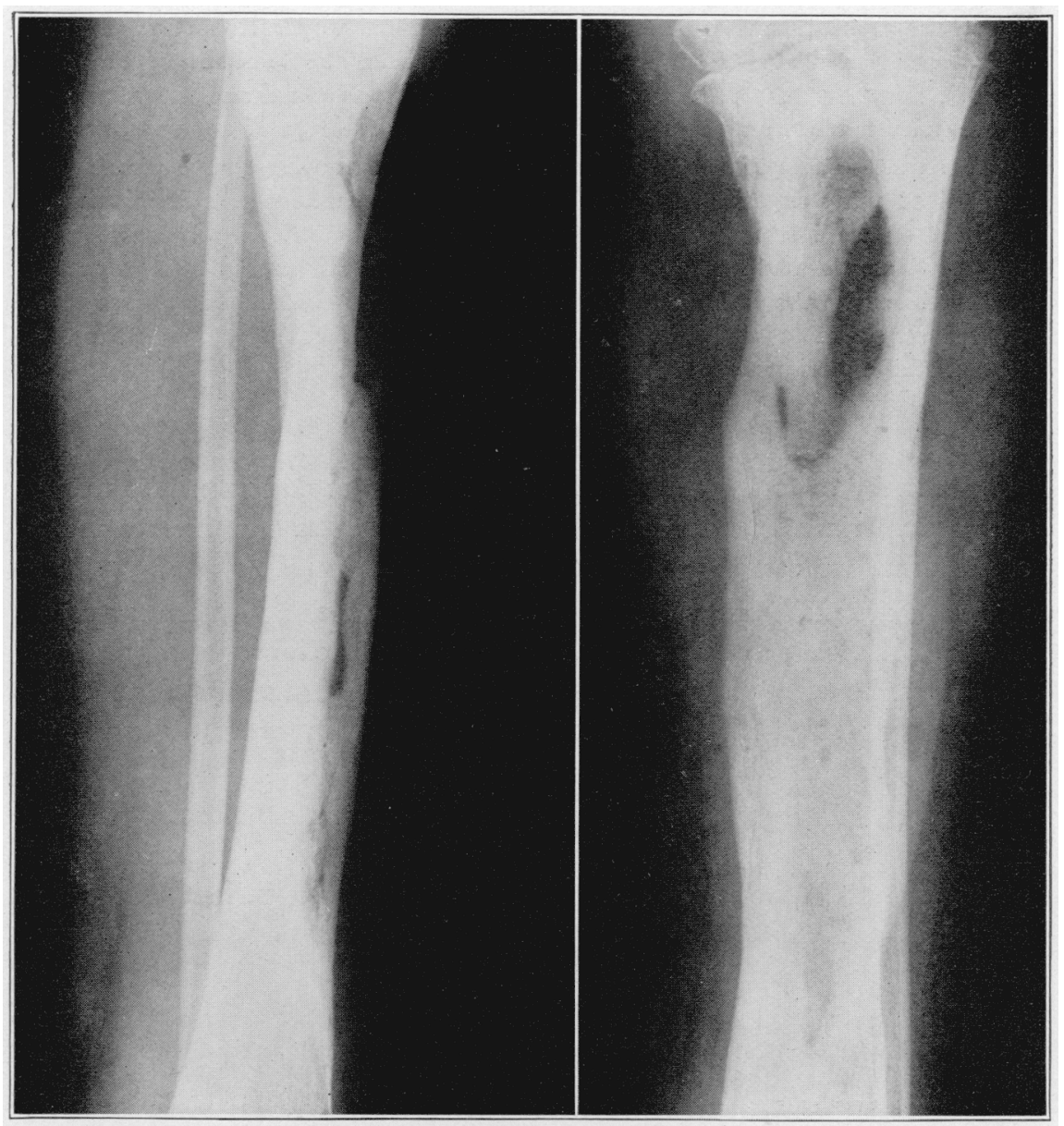

Fig. 29 (Case 2).-Roentgenogram taken. Oct. 18, 1920: new hone formation; wound healed; patient walking on leg: feels well.

Comment.-Primary roentgenographic stulies of this patient disclosed the appearance of rarefaction and secuestration in the lower third of the tibia. This completely disappeared without any operative interference.

Case 2 (Figs. 26 to 29).-A boy, aged 7 years, in whom the tibia had been insufficiently drained, elsewhere, for an acute ostcomyclitis, came into the hospital extremely ill, with a temperature of $106 \mathrm{~F}$., marked leukocytosis and 
prostration. At the primary operation, the entire anterior portion of the cortex of the tibia was removed. There was a fracture of the upper third due to the complete destruction of the bone. Periosteum was separated by pus from the greater part of the shaft. In this case Carrel tubes were inserted posteriorly between the necrotic shaft and the periosteum. The shaft appeared dead. It was not removed because it was thought advisable to maintain this portion of the shaft to prevent deformity. After about five weeks, granulations were seen springing up on the surface of the formerly necrotic shaft. Roentgenograms taken two months after the primary operation showed new bone formation about, and apparently incorporating, the remnant of the old necrotic shaft. At the present time, the patient has no sinus and the roentgen ray revealed marked new bone proliferation without the sign of any sequestrum.

Comment.-This patient, who was too sick to stand any operative procedurc, had a dead shaft exposed in the wound. After Dakinization, granulation tissue appeared on the former necrotic surface. The bone was later incorporated and the new bone formed about it. Whether or not in this case the sequestrum was sterilized by the Dakin solution, it is difficult to state; but it appears that it acted very much as did the chemical sequestrum produced by croton oil injections in the experimental laboratory.

\section{CONCLUSIONS}

From the experience obtained with these cases and from the many animal experiments, I am convinced that, in the future in the treatment of children, we can be more conservative.

First, adequate drainage should be obtained with as little trauma as possible. Second, in cases in which the patient is clinically progressing favorably, bone, which by roentgen-ray or gross examination, appears dead, may frequently be saved to advantage in order to prevent deformity and hasten convalescence.

Finally, I believe that in the past we have made bone repair appear much too complex. We have been lost in the by-ways of periosteum, endosteum and bone reticulum. It is much simpler to believe that bone occurs as a chemical deposition in connective tissue. Such a theory allows for bone formation as it appears in all parts of the body.

In bone transplants, we must assume that the transplant per se does not live but that it acts as a framework for new bone and stimulates osteogenesis. We must, therefore, apply grafts that can easily have a blood supply established, and have sufficient free surface to stimulate bone production.

In the treatment of fractures, care must be taken to increase the blood supply. This is more important than immobilization that constricts the limb. Early motion favors union for this reason.

What we are apparently doing when a bone graft is made or when extraskeletal bone occurs in an experiment is producing the right chemical state. Then the process of bone formation inevitably follows. 
Until the physical chemist tells us more of the intricacies of the chemistry of the tissues, the practical surgeon should study the circumstances of bone production, that is, what factors promote its formation. He should not let the disputes of the various experimenters over terms, or the question as to whether this or that tissue produces bone, confuse the issue. The issue requires that the patients be cured, following injury or infection of the bony structures.

100 East Sixty-Sixth Street. 